
\title{
ECJSE
}

Makale / Research Paper

\section{Hava Taşıtlarının Denizaltı Pasif Akustik Sistemle Uzaktan Algılanma Mesafelerinin İncelenmesi}

\author{
Yiğit MAHMUTOĞLU* \\ Recep Tayyip Erdoğan Üniversitesi, Mühendislik-Mimarlık Fakültesi, Elektrik-Elektronik Mühendisliği Bölümü \\ 53100 Rize/TÜRKIYE \\ yigit.mahmutoglu@erdogan.edu.tr
}

Received/Geliș: 13.08.2020

Accepted/Kabul: 09.10.2020

Öz: Dünyamızın yaklaşık 2/3'ünü kaplayan denizler birçok canlı türünü içinde barındığı gibi insan yapımı olan birçok yapıyı da içinde ve üstünde taşımaktadır. Günümüzde sualtı ortamında pasif akustik dinleme sualtı boru hatlarındaki sızıntıların algılanması/konumlandırılması, gemilerin algılanması, deniz canlılarının takip edilmesi gibi birçok uygulamada kullanılmaktadır. Zaten kurulu olan bu sistemlerde algılanabilecek başka bir akustik kaynak ise hava taşıtlarıdır. Denizin üstünde belirli mesafelerde uçan hava taşıtlarının ürettikleri akustik ses seviyeleri ihmal edilemeyecek düzeylerdedir. Ayrıca ses sinyali hava ortamından su ortamına geçerken ses basıncının genliği ikiye katlanmaktadır. Bu durum da hava taşıtlarının suyun altından daha kolay algılanabilmelerine izin vermektedir. Böylece izinsiz olarak başka ülkelerin sınırlarını deniz üstünden ihlal eden hava taşıtları algılanıp konumlandırılabilir. Bu çalışmada bir helikopter (Bell 212) ve üç farklı sabit kanatlı pervaneli uçak (B-N Islander, Twin Otter, P-3 Orion) olmak üzere dört farklı hava taşıtııın sualtından algılanma mesafeleri hakkında bir inceleme yapılmıştır. Böylece denizaltı ortamında kullanılabilecek bir hava taşıtı konumlandırma sistemi için bir ön çalışma yapılmıştır. Bu incelemeye göre ilgili hava taşıtlarının sualtından 219 $-790 \mathrm{~m}$ aralığındaki mesafelerden algılanabildiği gösterilmiştir.

Anahtar Kelimeler: Hava taşıtları; sualtı; pasif akustik; uzaktan algılama

\section{Investigation of Remote Sensing Distances of Aircrafts With Underwater Passive Acoustic System}

\begin{abstract}
The seas, which covers approximately 2/3 of our world, contain many living species as well as many human-made structures. Today, passive acoustic listening in underwater environment is used in many applications such as detection/positioning of leaks in underwater pipelines, detection of ships, monitoring of marine animals. Another acoustic source that can be detected with these already installed systems is aircraft. The acoustic sound levels produced by aircraft flying at certain distances above the sea are at a level that cannot be neglected. In addition, the amplitude of the sound pressure doubles as the sound signal passes from the air environment to the water environment. This allows aircraft to be detected more easily under water. Thus, aircraft that violate the borders of other countries over the sea without permission can be detected and located. In this study, an investigation was made on the detection distances of four different aircraft, a helicopter (Bell 212) and three various fixed wing propeller aircraft (B-N Islander, Twin Otter, P-3 Orion) from underwater. Thus, a preliminary study has been made for an aircraft positioning system that can be used in the underwater environment. According to this study, it has been shown that the relevant aircraft can be detected underwater from distances between 219-790 $\mathrm{m}$.
\end{abstract}

Keywords: Aircrafts; underwater; passive acoustics; remote sensing 


\section{Giriş}

Günümüzde sualtı ortamında pasif akustik dinleme sualtı boru hatlarındaki sızıntıların algılanmasi/konumlandırılmas1 [1,2], gemilerin algilanmas1 [3,4], deniz canlılarının takip edilmesi [5,6] gibi birçok uygulamada kullanılmaktadır. Zaten kurulu ve kullanılmakta olan bu pasif akustik sistemlerle algılanabilecek başka bir akustik kaynak ise hava taşıtlarıdır. Denizin üstünde belirli mesafelerde uçan hava taşıtlarının ürettikleri akustik ses seviyeleri ihmal edilemeyecek düzeylerdedir. Ayrıca ses sinyali hava ortamından su ortamına geçerken ses basıncının genliği ikiye katlanmaktadır [7]. Bu durum da hava taşıtlarının suyun altından daha kolay algılanabilmelerine izin vermektedir. Özellikle radarlardan kaçmak için alçaktan uçan kaçakçılık vb. yasadışı işlerde kullanılan hava taşıtlarının algılanması için bu hazır pasif dinleme sistemleri kullanılabilir. Böylece izinsiz olarak başka ülkelerin sınırlarını deniz üstünden ihlal eden hava taşıtları tespit edilip konumlandırılabilir. Konumlandırmanın temelini ise sinyal kaynağının algılanma mesafesi oluşturmaktadır. $\mathrm{Bu}$ nedenle hava taşıtlarının konumlandırılabilmeleri için ilk olarak hangi mesafelerden algılanabildiklerinin incelenmesi önem taşımaktadır.

Literatürde konumlandırma problemlerinde hem hava hem de sualtı ortaminda genellikle elektromanyetik, optik ve akustik sistemler kullanılmaktadır [8]. Ancak, elektromanyetik dalga hava ortamında çok uzak mesafelere kadar ilerleyebilmesine rağmen elektromanyetik dalganın sualtı ortamındaki iletim mesafesi yaklaşık $10 \mathrm{~m}$ ile sınırlıdır [9]. Yani elektromanyetik sistemler sualtında çok sınırlı bir iletim mesafesine sahiptir. Elektromanyetik sistemlerle karşılaştırıldığında daha düşük verici gücü gerektiren optik sistemler de sualtı ortamında sadece $100 \mathrm{~m}$ civarında iletim mesafesine sahiptir [9]. Ayrıca bu mesafe suyun bulanıklığına bağlı olarak azalabilir. Diğerleriyle kıyaslandığında akustik dalganın sualtı ortamında kilometrelerce uzaklıklara kadar yayılması akustik sistemi onlardan ayıran en önemli farktır. Bu durum da elektromanyetik sistemlerden daha düşük ancak optik sistemlerden daha yüksek verici gücü gerektiren akustik sistemler kullanılarak hedeflerin sualtı ortamında çok uzak mesafelerden algılanabileceği anlamına gelir [9]. Tüm bunların haricinde ise zaten sualtı ortamında kullanılmakta olan pasif akustik dinleme sistemlerinin uçak algılama problemi için kullanılması sistem maliyetini de minimize etmektedir. Bu nedenle istemsiz olarak akustik sinyal üretip bir akustik sinyal kaynağı gibi davranan hava taşıtlarının sualtından algılanması için (pasif) akustik sistemlerin kullanılması uygundur.

Hava taşıtlarında kullanılan pistonlu ve türbinli motorların oluşturduğu motor ve pervane sesleri bu taşıtları istemsiz birer akustik ses kaynağı haline getirmektedir. Literatürde hava taşıtlarının akustik sinyalleri kullanılarak, sualtından hava taşıtlarının algılanması ve konumlandırılması konusu sadece [10] çalışmasında ele alınmıştır. [10]'da aralarında $7.6 \mathrm{~m}$ mesafe bulunan 24 tane hidrofondan oluşan bir dizi kullanılmıştır. Direk yol sinyalini ve deniz tabanından yansıyan sinyali içeren iki farklı kanal modelinin ele alındığı çalışmada pervaneli bir uçak algılanmış ve konumlandırılmıştır. [11] ve [12]'de ise uçaklardan yayılan akustik sinyallerin sualtı ortamından ölçülmesi ve özellikle bu seslerin çok daha yoğun olduğu denize yakın havaalanlarının çevresindeki seslerin deniz canlıları üstündeki etkileriyle ilgili çalışmalar yapılmıştır. [10]'da algılama işlemi tek bir uçak tipi için yapılmıştır. Buna ek olarak alınan gücün farklı parametreler için değişimi detaylı olarak incelenmemiştir. Bu çalışmada bir helikopter (Bell 212) ve üç farklı sabit kanatlı pervaneli uçak (BN Islander, Twin Otter, P-3 Orion) olmak üzere, sualtı ortam gürültü eşiği eşliğinde, dört farklı hava taşıtının sualtından algılanma mesafeleri hakkında bir inceleme yapılmıştır. Böylece denizaltı ortamında kullanılabilecek bir hava taşıtı konumlandırma sistemi için bir ön çalışma yapılmıştır. Genel anlamda konumlandırma problemi oldukça güncel bir konudur [13]. Literatürde, karasal ortamda elektromanyetik dalgayla uçak takibinde sensörlerin algılama için efektif bir şekilde yerleştirilmesi üstüne çalışmıştır [14]. Ancak denizaltı ortamında kullanılabilecek bir hava taşıtı konumlandırma sistemiyle ilgili benzeri bir çalışma bulunmamaktadır. Bu nedenle bu çalışma aynı zamanda ileride yapılacak hava taşıt konumlandırma sistemlerinde alıcı konumlarının optimize edilmesi problemi için de bir ön çalışma niteliği taşımaktadır. Bu çalışma takip eden biçimde 
düzenlenmiştir. 2. bölümde hava taşıtı kaynaklı akustik sinyal hakkında bilgi verilmiştir. 3. bölümde ses sinyalinin hava ve sualtı ortamlarındaki yayılımı ve zayıflamasından bahsedilip, sualtı ortam gürültüsü hakkında bilgi verilmiştir. 4. bölümde yapılan benzetim çalışmasının sonuçları verilmiş̧ ve 5. bölümde sonuçlar özetlenmiştir.

\section{Hava Taşıtı Kaynaklı Akustik Sinyal}

Hava taşıtlarının motorları pistonlu ve türbinli olmak üzere ikiye ayrılır. Her motor tipi ya pervaneleri yada helikopter rotorunu döndürür. Türbinli motorlar aynı zamanda turbo jet veya turbo fan da olabilir ve bu tip motorlar pervane döndürme işlemini yapmaz [15]. Jetlerde kullanılan bu motor tipleri bu çalışmada göz önüne alınmamıştır. Pistonlu motorların seslerini ağırlıklı olarak, ses spektrumunda harmonikler oluşturan silindir ateşleme oranı oluşturmaktadır. Türbinli motorların seslerini pervane vınlama sesi karakterize eder. Birkaç yüz Hz'den 1 kHz'in biraz üstüne kadar uzanan bir spektruma sahiptir. Pervaneye sahip helikopterler ve sabit kanatlı uçakların oluşturduğu gürültünün baskın olarak bulunduğu spektrum $500 \mathrm{~Hz}$ 'in altındadır. Bu hava taşıtlarının ürettiği akustik sinyallerin güçlerinin büyük bir kısmı rotor veya pervane dönme oranına bağlı olan belirli frekans bileşenlerinde bulunmaktadır [15]. Bu çalışmada ele alınan hava taşıtlarının oluşturduğu akustik sinyallerin güçleri ve güçlerin büyük bir kısmının bulundukları frekans bileşenleriyle ilgili ölçüm değerleri Tablo 1'de verilmiştir [15].

Tablo 1. Çeşitli hava taşıtlarının oluşturduğu akustik sinyallerin güçleri ve ilgili frekans bileşenleri [15]

\begin{tabular}{lcc}
\hline Hava taşıtı & Frekans bileşeni $(\mathbf{H z})$ & Sinyal gücü (dB re $\mathbf{1} \boldsymbol{\mu P a})$ \\
\hline Bell 212 & 22 & 149 \\
B-N Islander & 70 & 142 \\
Twin Otter & 82 & 147 \\
P-3 Orion & 68 & 162 \\
\hline
\end{tabular}

\section{Hava ve Sualtı Akustik Kanalları}

\subsection{Hava Akustik Kanalı}

Hava ortamında yayılan akustik sinyaller için yayılım kaybı (ses dalgasının vericiden alıcıya direk olarak gittiği durum göz önüne alınır ve rüzgar ve sıcaklık değişimleri ihmal edilirse) geometrik zayıflama (bu çalışmada küresel zayıflatma olarak alınmıştır) ve atmosferik emilim olmak üzere iki ana bileşenden oluşur [16]. Yayılım kaybı olan $Y K_{h}$ denklem (1)'deki gibi ifade edilmektedir [15]. $\mathrm{Bu}$ çalışmada deniz sınırındaki akustik sinyal seviyesinin hava ortam gürültü seviyesinden büyük olduğu kabul edilmiştir. Bu nedenle hava ortam gürültüsü ihmal edilmiştir.

$$
Y K_{h}=20 \log _{10}\left(d / d_{0}\right)+a_{h} d
$$

Burada $d$ verici ve alıcı arası mesafe $(\mathrm{m}), d_{0}$ referans mesafe $(\mathrm{m})$ ve $a$ zayıflatma katsayısıdır. $a_{h}$ zayıflatma katsayısı dB/m cinsinden aşağıdaki gibi hesaplanmaktadır [17].

$$
\begin{gathered}
a_{h}(f)=8.686 f^{2}\left[1.84 \times 10^{-11}\left(\frac{p_{a}}{p_{r}}\right)^{-1}\left(\frac{T}{T_{r}}\right)^{\frac{1}{2}}\right]+\left(\frac{T}{T_{r}}\right)^{-\frac{5}{2}} \\
\left\{0.01275\left[e^{\left(-\frac{2239.1}{T}\right)}\right]\left[f_{r o} /\left(f_{r o}^{2}+f^{2}\right)\right]+0.1068 e^{(-3352 / T)}\left[f_{r N} /\left(f_{r N}^{2}+f^{2}\right)\right]\right\}
\end{gathered}
$$


Burada $f$ ses zayıflatmasının hesaplanacağı frekans $(\mathrm{Hz}), \quad p_{a}$ ortam atmosferik basınc1 $(k P a)$, $p_{r}=101.325 \mathrm{kPa}$ referans ortam basinc1, $T$ ortam atmosferik sicaklığ $1\left({ }^{\circ} \mathrm{K}\right), T_{r}=293.15^{\circ} \mathrm{K}$ referans ortam sıcaklığıdır [16]. $f_{r o}$ ve $f_{r N}$ sirasıyla denklem (3) ve (4)'te verilmiştir.

$$
\begin{gathered}
f_{r O}=\left(\frac{p_{a}}{p_{r}}\right)\left\{24+\left[\left(4.04 \times 10^{4} h\right)(0.02+h) /(0.391+h)\right]\right\} \\
f_{r N}=\left(\frac{p_{a}}{p_{r}}\right)\left(\frac{T}{T_{r}}\right)^{-\frac{1}{2}}\left(9+280 h e^{-4.17\left[\left(\frac{T}{T_{r}}\right)^{-\frac{1}{3}}-1\right]}\right)
\end{gathered}
$$

$h$ yüzde olarak su buharının molar yoğunluğu olup denklem (5)'te verilmiştir.

$$
h=h_{r e l}\left(p_{\text {sat }} / p_{r}\right)\left(p_{a} / p_{r}\right)^{-1}
$$

Burada $h_{r e l}$ yüzde olarak bağıl nemdir. $p_{\text {sat }}$ ise denklem (6)'da verilmiştir. $V$ denklem (7)'de verilmiştir.

$$
\begin{gathered}
p_{\text {sat }}=\left(p_{r}\right) 10^{V} \\
V= \\
10.79586\left[1-\left(T_{01} / T\right)\right]-5.02808 \log _{10}\left(\frac{T}{T_{01}}\right)+1.50474 \times 10^{-4}\left\{1-10^{-8.29692\left[\left(\frac{T}{T_{01}}\right)-1\right]}\right\}+ \\
0.42873 \times 10^{-3}\left\{-1+10^{\left.4.76955\left[1-\left(\left(\frac{T_{01}}{T}\right)-\right)\right]\right\}-2.2195983}\right.
\end{gathered}
$$

burada $T_{01}$ üç nokta izoterm sicaklığı olup üç bileşenli faz diyagramında sicaklığa bağlı olarak üç bileşen arasında meydana gelen çeşitli fazlar arasındaki dengeyi ifade eden sıcaklıktır. Bu çalışmada [17]'ye benzer olarak $T_{01}=273.16^{\circ} \mathrm{K}$ olarak alınmıştır.

\subsection{Sualtı Akustik Kanalı}

Sualtı ortamında yayılan akustik sinyaller belirli bir yayılım kaybına maruz kalıp alıcıya ulaşır. Buna ek olarak alıcıda ortam gürültüsü de etkili olur. Sualtı ortamında yayılan akustik sinyaller için yayılım kaybı, geometrik zayıflama ve emilim kaybından oluşup denklem (8)'deki gibi verilmektedir [18].

$$
Y K_{s}=20 \log _{10}\left(d / d_{0}\right)+\left(a_{s} / 1000\right) d
$$

Burada $d$ verici ve alıcı arası mesafe $(\mathrm{m}), d_{0}$ referans mesafe $(\mathrm{m})$ ve $a$ zayıflatma katsayısıdır. $a_{s}$ zayıflatma katsayısı dB/km cinsinden denklem (9)'daki gibi hesaplanmaktadır [18]. Burada $f \mathrm{kHz}$ cinsindendir.

$$
a_{s}(f)=\frac{0.11 f^{2}}{1+f^{2}}+\frac{44 f^{2}}{4100+f^{2}}+\frac{2.75 f^{2}}{10^{4}}+0.003
$$

Sualtı ortamındaki gürültü kaynaklarının birçoğu, sürekli bir güç spektral yoğunluğuna sahip olup Gauss dağılımıyla modellenmektedir. Sualtındaki en düşük ortam gürültüsü, rüzgarsız durumdaki dalga gürültüsü ve termal gürültünün birleşiminden oluşmaktadır [19]. Ortam gürültüsü bu çalışmada dalga ve termal gürültülerinin birleşimi olarak alınmıştır. Denklem (10) ve (11)'de dB re $1 \mu \mathrm{Pa} / \mathrm{Hz}$ cinsinden dalga ve termal gürültülerinin güç spektral yoğunlukları verilmiştir [18]. Burada $u \mathrm{~m} / \mathrm{s}$ cinsinden rüzgar hızıdır (bu çalışmada orta ölçekli yüzey dalgasına neden olan $u=9.8 \mathrm{~m} / \mathrm{s}$ kullanıldı). Sualtı ortam gürültüsünün toplam güç spektral yoğunluğu denklem (12)'de verilmiştir.

$$
10 \log _{10} N_{d}=50+7.5 u^{1 / 2}+20 \log _{10} f-40 \log _{10}(f+0.4)
$$




$$
\begin{gathered}
10 \log _{10} N_{t}=-15+20 \log _{10} f \\
N=N_{d}+N_{t}
\end{gathered}
$$

\section{Benzetim Çalışmaları}

Bu çalışmada, Şekil 1'de gösterildiği üzere, hava taşıtlarının ürettiği akustik sinyalleri algılamak için kullanılan alıcıların deniz üstüne yerleştirilen yüzey istasyonlarından denizin $25 \mathrm{~m}$ altına sarkıtıldığı varsayılmıştır. Denizin yeterince derin olduğu yani deniz ortamına giren akustik sinyallerin deniz tabanına ulaşamadan tamamen zayıfladığ 1 bu nedenle alıcıya ulaşan sinyaller içinde yansıyan bileşen olmadığı varsayıldı. Akustik sinyal alıcı tarafindan algılanınca bu sinyal yüzey istasyonuna iletilip burada değerlendirilmiştir. [15]'te hava taşıtlarının ürettiği akustik sinyallerin güçlerinin büyük bir kısmının belirli frekans bileşenlerinde bulunduğu ve bu frekansların $500 \mathrm{~Hz}$ 'in altında olduğu belirtilmiştir. Bu nedenle alınan sinyaller 0-500 Hz bandını tarayan $1 \mathrm{~Hz}$ bant genişliğine sahip bir bant geçiren süzgeçten geçirilirler. Böylece ilgili bandın dışındaki tüm sinyaller ve gürültüler süzgeçlenir. Süzgecin bant genişliğinin $1 \mathrm{~Hz}$ seçilmesinin nedeni hava taşıtlarının ürettiği akustik sinyallerin güçlerinin büyük bir kısmının belirli frekans bileşenlerinde bulunmasidir.
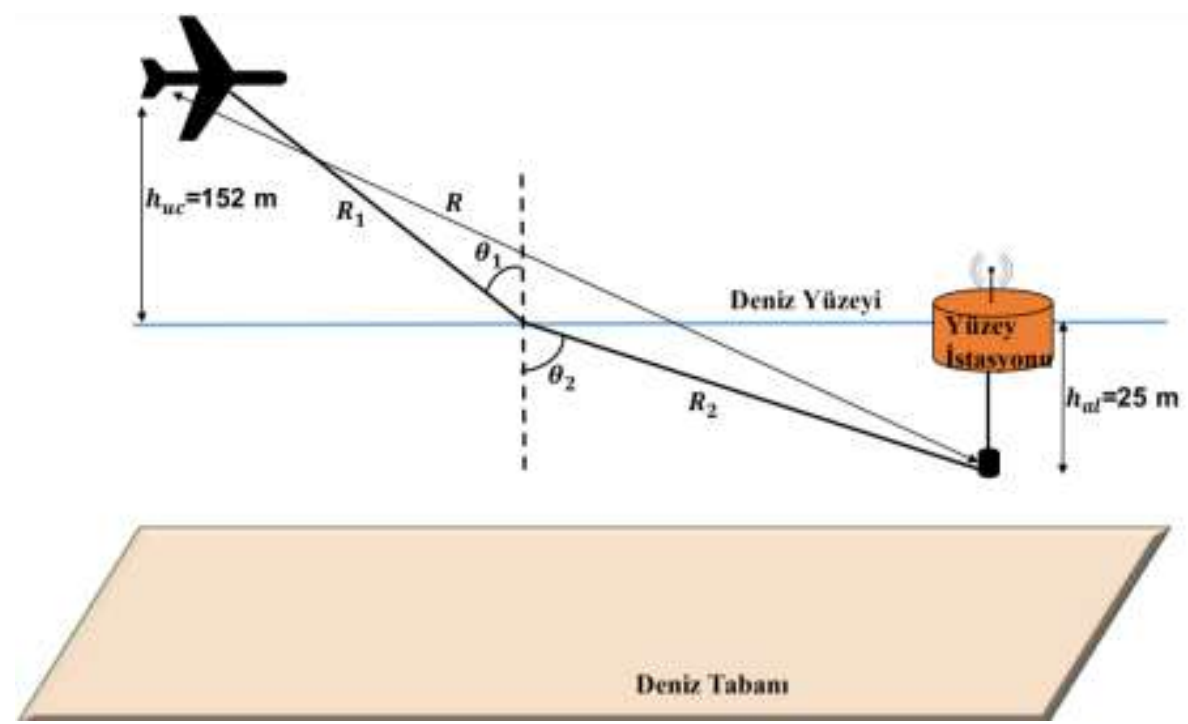

Şekil 1. Sistem yapısı ve geometrisi

Tablo 2. Benzetim çalışmalarında kullanılan parametre değerleri

\begin{tabular}{lc}
\hline Parametre & Değer \\
\hline Hava ortamında ses hızı $\left(c_{h}\right)$ & $344 \mathrm{~m} / \mathrm{s}$ \\
Su ortamında ses hızı $\left(c_{s}\right)$ & $1500 \mathrm{~m} / \mathrm{s}$ \\
Alıcı derinliği $\left(h_{a l}\right)$ & $25 \mathrm{~m}$ \\
Hava taşıtının yüksekliği $\left(h_{u c}\right)$ & $152 \mathrm{~m}$ \\
Yer çekimi ivmesi $(g)$ & $9.8 \mathrm{~m} / \mathrm{s}^{2}$ \\
Referans basınç $\left(p_{r}\right)$ & $101.325 \mathrm{kPa}$ \\
Referans sıcaklık $\left(T_{r}\right)$ & $293.15^{\circ} \mathrm{K}$ \\
Ortam atmosferik sıcaklığı $(T)$ & $290.15^{\circ} \mathrm{K}$ \\
Ortam atmosferik basıncı $\left(p_{a}\right)$ & $99.55 \mathrm{kPa}$ \\
Üç nokta izoterm sıcaklığı $\left(T_{01}\right)$ & $273.16^{\circ} \mathrm{K}$ \\
Bağıl nem $\left(h_{r e l}\right)$ & $\% 75$ \\
Rüzgar hızı $(u)$ & $9.8 \mathrm{~m} / \mathrm{s}$ \\
\hline
\end{tabular}


Matlab ortamında yapılan benzetim çalışmalarında bir helikopterin ve 3 farklı uçağın ürettikleri akustik sinyallerin güçlerine bağlı olarak hava taşıtı ve alıcı arasındaki eğik mesafe, geliş açısı ve hava taşıtı ve alıcı arasındaki gerçek mesafe arasındaki ilişkiler incelenmiştir.

Benzetim çalışmalarında kullanılan Bell 212 (helikopter), B-N Islander, Twin Otter ve P-3 Orion olmak üzere dört farklı hava taşıtının ürettikleri akustik sinyallerin bulundukları frekanslar ve seviyeleri Tablo 1'de verilmiştir. Buna göre B-N islander, twin otter ve P-3 orion'un ürettiği akustik sinyallerin frekansları sırasıyla $70 \mathrm{~Hz}, 82 \mathrm{~Hz}$ ve $68 \mathrm{~Hz}$ olup birbirine yakın olduğundan frekansa bağlı olarak değişen ortam gürültü seviyeleri de birbirine yakındır. Bu nedenle, ilgili değerlere bakılarak B-N islander, twin otter ve P-3 orion için sualtı ortam gürültüsü olan $N 1$ 'in seviyesi $64 \mathrm{~dB}$ re $1 \mu \mathrm{Pa}$ olarak alınmıştır. Bell 212'nin ürettiği akustik sinyalin frekansı $(22 \mathrm{~Hz})$ diğerlerine göre daha farklıdır. Bu nedenle ilgili frekans için sualtı ortam gürültüsü olan N2'nin seviyesi $55.3 \mathrm{~dB}$ re $1 \mu \mathrm{Pa}$ olmaktadır. Benzetimde kullanılan tüm parametreler Tablo 2’de verilmiştir.

Snell yasasına göre $\sin \left(\theta_{1}\right) / \sin \left(\theta_{2}\right)=c_{h} / c_{s}$ formülünden ses hızlarına bağlı olarak geliş veya yansıma açıları hesaplanabilir. Denizin dalgasız olduğu durumda, eğer uçaktan gelen ses dalgasının geliş açısı kritik açıyı geçerse gelen ses dalgasının tamamı deniz yüzeyinden yansır ve ses dalgası deniz ortamına geçemez [15]. Bu kritik açı hava ortamındaki ses hızı $\left(c_{h}\right)$ ve su ortamındaki ses hızına $\left(c_{s}\right)$ göre $\theta_{c}=\sin ^{-1}\left(c_{h} / c_{s}\right) \cong 13.25^{\circ}$ olur. Yani Şekil 1'de verilen $\theta_{1}$ açısı en fazla $13.25^{\circ}$ olabilir. Bu nedenle benzetim çalışmalarında uçak ve alıcı arasındaki en uzak mesafe bu açı dikkate alınarak belirlenmiştir. $\theta_{1}$ ve $\theta_{2}$ açısı arasındaki ilişki Snell'in yasasına göre $\theta_{1}=\sin ^{-1}\left(\left(c_{h} /\right.\right.$ cs) $\sin \theta 2$ eşitliğinden elde edilir.

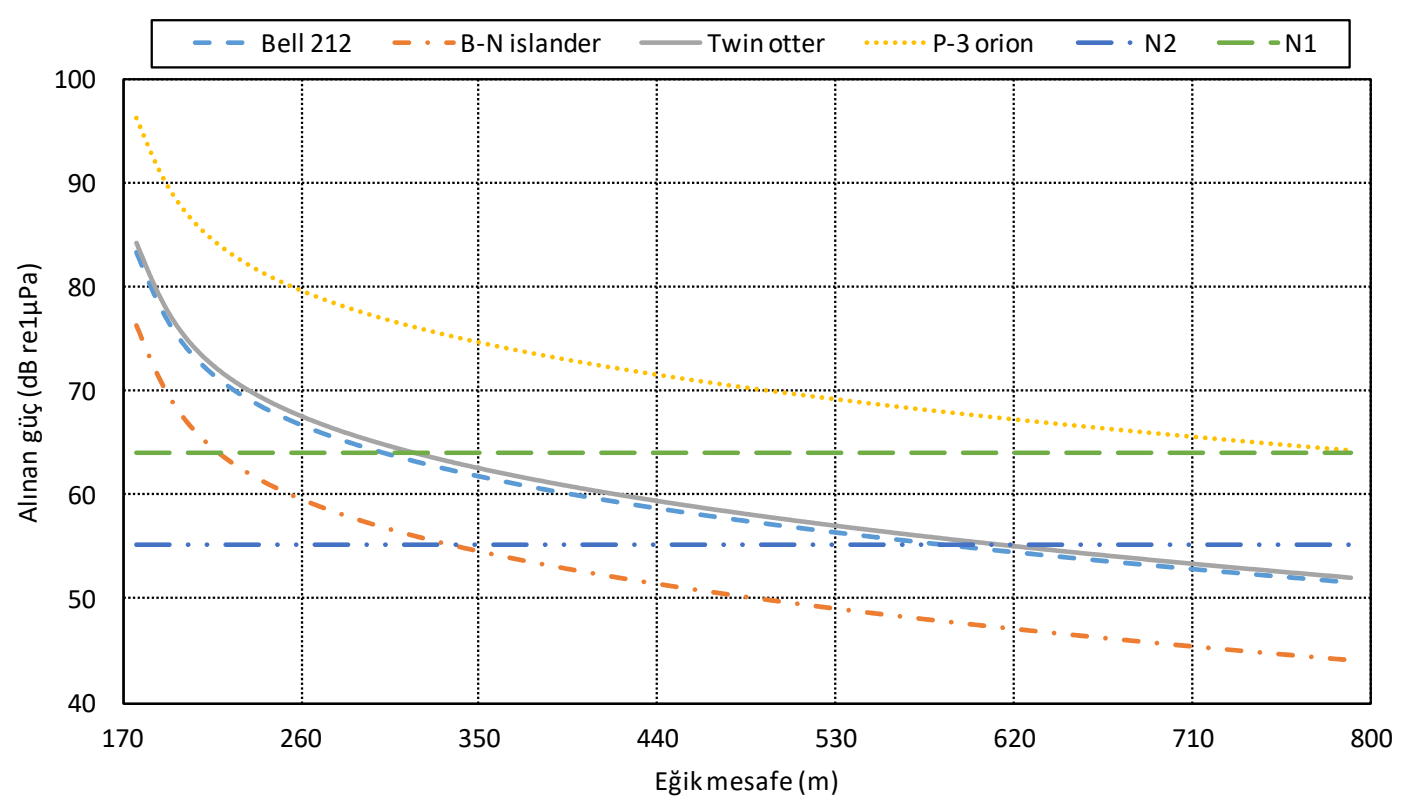

Şekil 2. Hava taşıtı ve alıcı arasındaki eğik mesafeye $(R)$ göre alınan gücün değişsimi

Tablo 1 ve 2'deki veriler göz önüne alınarak, Şekil 2'de $R$ ile ifade edilen hava taşıtı ve alıcı arasındaki eğik mesafeye göre alınan gücün değişimi $N 1$ ve $N 2$ ortam gürültüsü değerlerine göre verilmiştir. Buna göre Bell 212, B-N Islander, Twin Otter ve P-3 Orion için uzaktan algılanma mesafeleri sırasıyla $538 \mathrm{~m}, 219 \mathrm{~m}, 318 \mathrm{~m}$ ve 790 m'dir. Yani en yüksek ve en düşük algılanma mesafelerine sırasıyla P-3 Orion ve B-N Islander'ın sahip olduğu görülmektedir. 


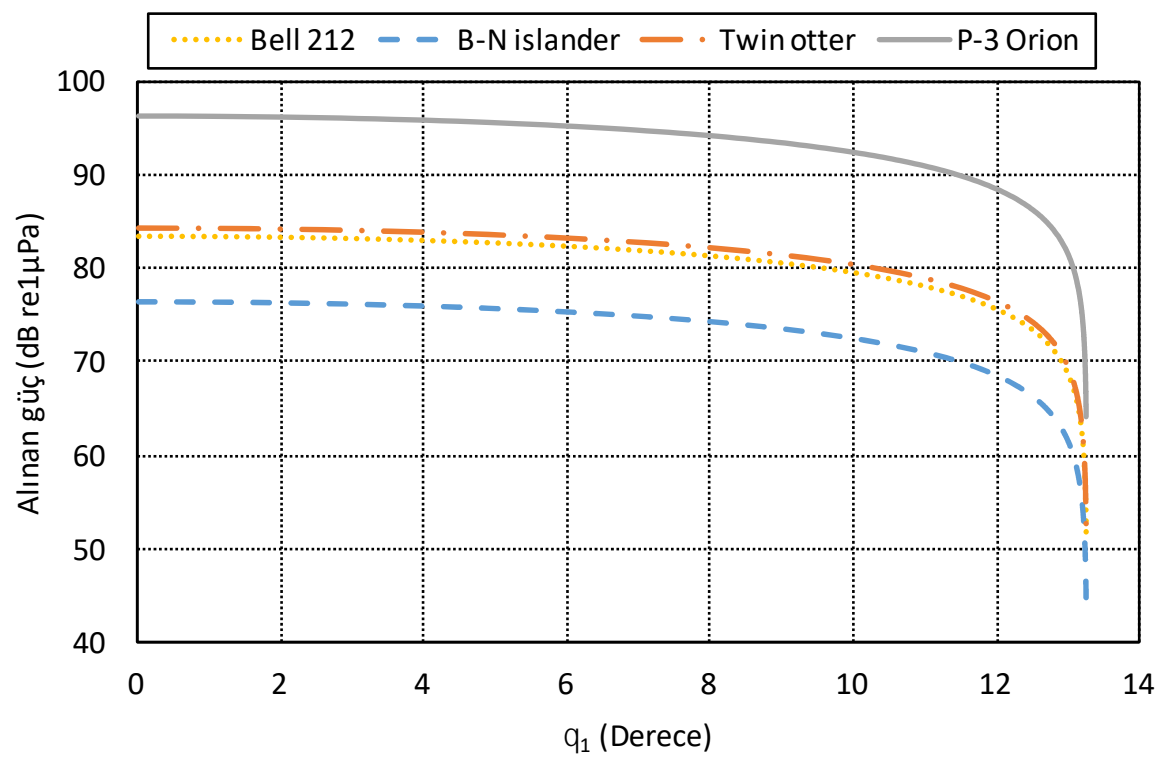

Şekil 3. $\theta_{1}$ açısına göre alınan gücün değişimi

Hava taşıtı ve alıcı arasındaki mesafe arttıkça geliş açısı $\left(\theta_{1}\right)$ da artmaktadır. Şekil 3'te alınan gücün değişimi geliş açısı $\left(\theta_{1}\right)$ 'e bağlı olarak verilmiştir. Kritik açı durumundan dolayı $\theta_{1}$ $13.25^{\circ}$ 'den daha büyük değerler aldığında alınan güç sıfır olacaktır. Bu nedenle $\theta_{1}$ 'in üst değeri $13.25^{\circ}$ olarak alınmıştır. Hava taşıtı ve alıcı arasındaki eğik mesafe $R$ mesafesidir ancak ses dalgasının aldığı gerçek mesafe $R_{1}+R_{2}$ kadardır. Şekil 4 'te $R_{1}+R_{2}$ mesafesine göre alınan gücün değişimi $N 1$ ve $N 2$ ortam gürültüsü değerlerine göre verilmiştir. Buna göre aslında Bell 212, B-N Islander, Twin Otter ve P-3 Orion hava taşıtlarından çıkan ses dalgalarının yayılıp alıcılara ulaştıkları gerçek mesafeler sırasıyla $672 \mathrm{~m}, 253 \mathrm{~m}, 386 \mathrm{~m}$ ve $890 \mathrm{~m}$ olmaktadır. Bulunan bu mesafe değerlerinin en yüksek değerler olduğu unutulmamalıdır. Yağmur, deniz canlıları gibi diğer gürültü kaynaklarının oluşturacağı gürültüler bu mesafe değerlerinin azalmasına neden olacaktır.

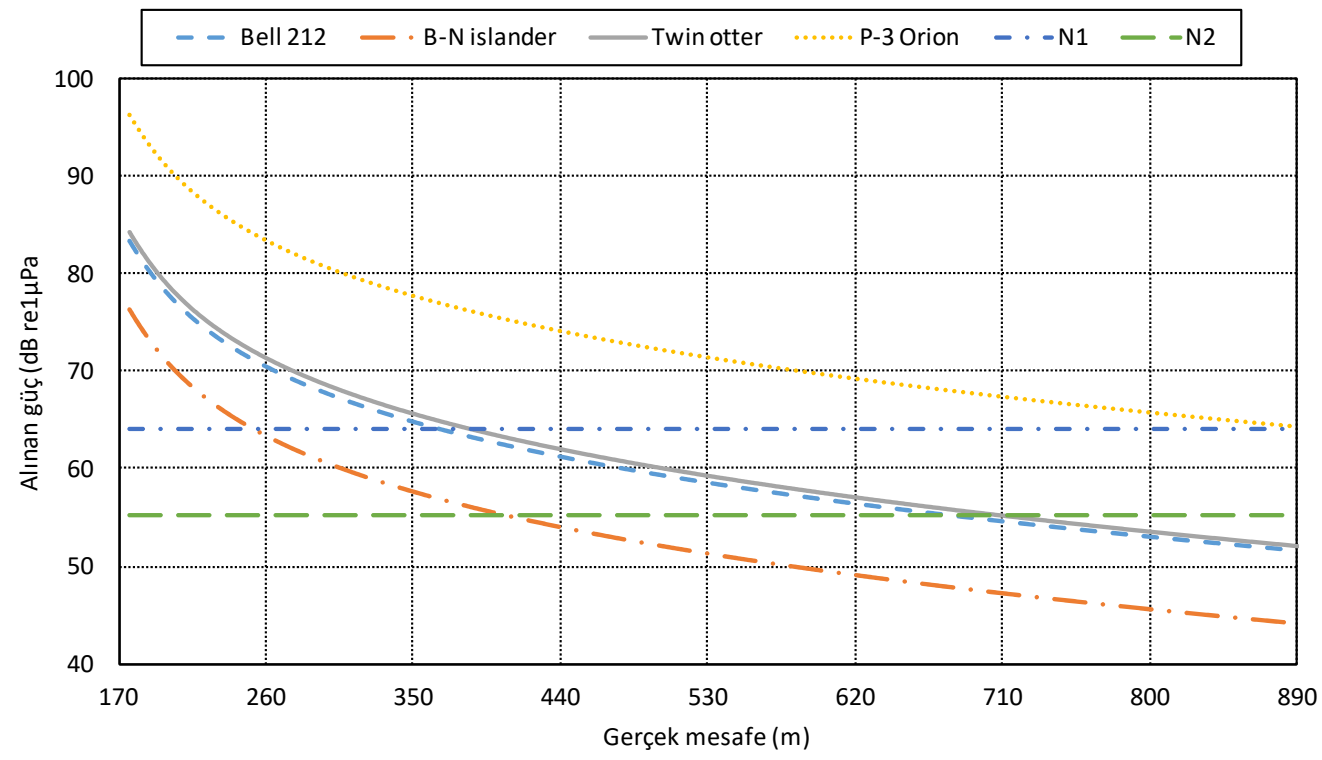

Şekil 4. Gerçek mesafeye $\left(R_{1}+R_{2}\right)$ göre göre alınan gücün değişimi

\section{Sonuçlar}

Bu çalışmada bir helikopter (Bell 212) ve üç farklı sabit kanatlı pervaneli uçak (B-N Islander, Twin Otter, P-3 Orion) olmak üzere dört farklı hava taşıtının sualtından algılanma mesafeleri hakkında bir inceleme yapılmıştır. Bu incelemeye göre ilgili hava taşıtlarının sualtından $219-790 \mathrm{~m}$ aralığındaki 
mesafelerden algılanabildiği gösterilmiştir. Hava taşıtlarının takip edilmesi izinsiz olarak başka ülkelerin sınırlarını deniz üstünden ihlal etmelerinin önüne geçilmesi ve kaçakçılık gibi yasadışı ișlerin önlenmesi açılarından oldukça önemlidir. Hava tașıtlarını takip edebilmek için kurulacak bir konumlandırma sisteminin bu sonuçlara göre tasarlanması sistemin verimliliği ve maliyeti için önem taşımaktadır. Buna ek olarak bu çalışmadan elde edilen sonuçlar ileride yapılacak hava taşıt konumlandırma sistemlerinde alıcı konumlarının optimizasyonu gibi problemler için bir temel niteliği taşımaktadır.

\section{Kaynaklar}

[1]. Mahmutoglu Y., Turk K., A passive acoustic based system to locate leak hole in underwater natural gas pipelines, Digital Signal Processing, 2018, 76: 59-65.

[2]. Mahmutoglu Y., Turk K., Positioning of leakages in underwater natural gas pipelines for time-varying multipath environment, Ocean Engineering, 2020, 207: 107454.

[3]. Oudomphengand B., Nicolas B., Lamotte L., Localization and contribution of underwater acoustical sources of a moving surface ship, IEEE Journal of Oceanic Engineering, 2018, 43(2): 536-546.

[4]. Zhu C., Garcia H., Kaplan A., Schinault M., Handegard N.O., Godo W.H.O.R., Ratilal P., Detection, localization and classification of multiple mechanized ocean vessels over continental-shelf scale regions with passive ocean acoustic waveguide remote sensing, Remote Sensing, 2018, 10(1699): 1-26.

[5]. Lohrasbipeydeh H., Mosayyebpour S., Gulliver T.A., Single hydrophone passive acoustic sperm whale range and depth estimation, IEEE International Conference on Acoustics, Speech and Signal Processing, 2012, Vancouver, Canada.

[6]. Tiemann C.O., Thode A.M., O'Connell V., Folkert K., Three-dimensional localization of sperm whales using a single hydrophone, The Journal of The Acoustical Society of America, 2006, 120(4): 2355-2365.

[7]. Brekhovskikh L.M., Lysanov Y.P., Chapter:3 Reflection of sound from the surface and bottom of the ocean: plane waves, Fundamentals of Ocean Acoustics, AIP Press, New York, USA, 2002.

[8]. Saeed N., Celik A., Al-Naffouri A., Alouini M., Underwater optical wireless communications, networking, and localization: A survey, AD Hoc networks, 2019, 57(8): 1-35.

[9]. Kaushal H., Kaddoum G., Underwater optical wireless communication, IEEE Access, 2019, 94: 5894-5913.

[10]. Ferguson B.G., Speechley G.C., Acoustic Detection and Localization of a Turboprop Aircraft by an Array of Hydrophones Towed Below the Sea Surface, IEEE Journal of Oceanic Engineering, 2009, 34(1): 75-82.

[11]. Buckingham M.J., Giddens E.M., Pompa J.B., Simonet F., Hahn T.R., Sound from a Light Aircraft for Underwater Acoustics Experiments?, Acta Acustica United With Acustica, 2002, 88: 752-755.

[12]. Erbe C., Williams R., Parsons M., Parsons S.K., Hendrawan I.G., Underwater noise from airplanes: An overlooked source of ocean noise, Marine Pollution Bulletin, 2018, 137: 656661.

[13]. Tunç M., Kara F., Kaya H., Dinamik Yapay Sinir Ağı İle İç Mekan Konum Kestirimi, ElCezeri Fen ve Mühendislik Dergisi, 2020, 7(2): 858-870.

[14]. Tuysuz B., A New Target Radar Cross Section Based Passive Radar Surveillance Receiver Positioning Algorithm on Real Terrain Maps, Radioengineering, 2018, 27(3): 891-898.

[15]. Richardson W.J., Greene C.R., Malme C.I., Thomson D.H., Marine mammales and noise, 1, Academic Press, California, USA, 1995.

[16]. Kapoor R., Acoustic Sensors for Air and Surface Navigation Applications, Sensors, 2018, 18: 499. 
[17]. Rickley E.J., Fleming G.G., Roof C.J., Simplified Procedure for Computing Absorption of Sound by the Atmosphere, Noise Control Engineering Journal, 2007, 55 (6): 482-494.

[18]. Stojanovic M., On the relationship between capacity and distance in an underwater acoustic communication channel, 1st ACM InternationalWorkshop on Underwater Networks (WUWNet'06), 2006, Los Angeles, USA.

[19]. Sherman C.H., Chapter: 4 Transducers as hydrophones, Transducers and arrays for underwater sound, Springer, New York, USA, 2007. 